\title{
'Don't Blow Your Cool': Provocation, Violent Coping, and the Conditioning Effects of Self-Control
}

\author{
Sonja Schulz ${ }^{1}$
}

Published online: 12 October 2015

(C) The Author(s) 2015. This article is published with open access at Springerlink.com

\begin{abstract}
Objectives General Strain Theory (Agnew in Criminology 30:47-87, 1992) has received broad empirical support, but little is known about moderators of the strain-delinquency relationship. This study tests whether self-control attenuates the relationship between a certain type of delinquency-violence-and its most important precursor, considered a type of strain: interpersonal provocation. This study compares the conditioning effects of risk-affinity and self-control/impulsivity on the provocation-violence link, since recent work suggests differentiating between both characteristics.

Methods The provocation-violence link is examined (1) using a scenario design with randomly varied degrees of objective provocation and a measure of projected violence, and (2) with measures of self-reported past violence and subjective sensitivity to provocation. The analyses are based on a large sample of seventh-graders $(n=2635)$ from five cities in Western Germany, interviewed in 2013. Linear probability models regressing violence measures on personal traits, provocation measures, and their interactions are estimated.

Results Both self-control and risk-affinity moderate the relationship between subjective sensitivity to provocation and past violent behavior. Students with high self-control are able to control their anger and do not turn violent, even when they feel provoked easily. However, only risk-affinity significantly amplifies the effect of objective provocation on prospective violence when simultaneously controlling for the conditioning effect of selfcontrol.

Conclusions Findings underscore that both self-control and risk-aversion are important coping resources. This study highlights the importance of using internally consistent and mechanism-congruent measures in the study of illicit coping processes and conditioning factors and discourages from using composite, potentially multidimensional measures.
\end{abstract}

Sonja Schulz

sonja.schulz@gesis.org

1 Data Archive for the Social Sciences, GESIS - Leibniz-Institute for the Social Sciences, Unter Sachsenhausen 6-8, 50667 Cologne, Germany 
Keywords Self-control · Provocation · Violence · Individual differences · General Strain Theory

\section{Introduction}

In recent decades, General Strain Theory (GST, Agnew 1985, 1992) has received solid empirical support (e.g. Mazerolle and Piquero 1997; Mazerolle et al. 2000; Piquero and Sealock 2000; Hay 2003; Broidy 2001) and has become one of the leading explanations of crime and deviant behaviors. However, the problem of predicting when individuals will tend towards a delinquent coping response and the question of which stressors are particularly conducive to crime and delinquency have motivated Agnew to make extensions to the GST (Agnew 2001, 2006, 2013; Agnew et al. 2002). This concerns, amongst other extensions, the introduction of the idea that specific strains are more strongly related to corresponding types of crime, the differentiation between objective and subjective strain, and the stronger focus on interpersonal differences in coping resources.

One factor that can be expected to condition the reaction to strain is low self-control (Gottfredson and Hirschi 1990; Agnew 2006; DeWall et al. 2007; Denson et al. 2011b). Faced with irritation and strain, individuals with high self-control should be more prone to reflect on different action alternatives and to take into account the long-term costs of delinquent coping. People with low self-control should instead act on impulse and 'take the easy way out' of the unpleasant situation, which often results in crime and delinquency. Previous studies, however, provided inconsistent results on the conditioning effect of low self-control. Some studies were able to reveal an interaction effect between low selfcontrol and strain in the expected direction (e.g. Baron 2009; Hay and Meldrum 2010; Jang and Rhodes 2012; Moon et al. 2012; Turanovic and Pratt 2013), while others were not (e.g. Botchkovar et al. 2009; Stogner and Gibson 2010; Ellwanger and Pratt 2014).

Three factors may have contributed to this discrepancy in results. First, the use of composite indices of strain, as well as composite indices of 'general delinquency', should hamper the discovery of conditioning effects if the strains that are included in composite indices differ in their predictive quality with regard to the delinquent behaviors under study and/or the respective motives behind delinquent coping (Felson et al. 2012). Without knowing the reason for delinquent coping (in other words, why individuals solve their problems in a delinquent manner) it must likewise remain unclear which coping resource would make delinquent coping less likely; thus the choice of factors expected to condition the effects of strain on delinquency must become arbitrary. A similar problem pertains to the applied measures of self-control: prior studies often used composite, multi-dimensional measures of low self-control, which neglected potential mechanisms underlying its functioning as a coping resource. The most prominent example of such a composite measure is probably the self-control scale by Grasmick et al. (1993). Several studies have shown that the subdimensions of the Grasmick scale differ in their predictive quality with regard to deviant behaviors (Arneklev et al. 1993; Wood et al. 1993; Longshore et al. 1996; Piquero and Rosay 1998; Delisi et al. 2003; Bornewasser et al. 2007; Conner et al. 2009; Ward et al. 2014). It can therefore be expected that the subdimensions also differ with respect to their importance as coping resources. Therefore, the use of composite self-control measures containing subdimensions only weakly related or unrelated to the conditioning process might have masked existing relationships as well. Third, research on the 
moderators of the strain-delinquency relationship should profit from taking into account the subjective evaluation of strain. If the experienced objective strain is not considered severe, and if the individual does not experience an intense emotional reaction to strain, criminal coping is unlikely in the first place (Froggio and Agnew 2007) and there should be no need to exercise self-control.

The current study advances knowledge of whether self-control conditions the reaction to strain by addressing these three problems simultaneously. It considers a specific type of strain that is particularly conducive to violence (interpersonal esteem-threatening provocation), and matches it with the coping resource that is likely to be involved in not responding violently to this type of strain: self-control. Recent work suggests differentiating between the personality traits of risk-affinity and low self-control/impulsivity (Burt and Simons 2013; Burt et al. 2014; Ksinan et al. 2014; Schulz 2014; Felson and Osgood 2008), which were combined in such self-control measures as the Grasmick scale. Building on this line of work, this study contrasts the conditioning effect of low self-control/ impulsivity with that of risk-affinity. The link between provocation and violence is studied with subjective and objective measures of provocation. The analyses are structured in two parts: First, the link between provocation and violence is analyzed with a measure of subjective sensitivity to provocation and self-reports of past violent behavior. Second, projected violence within a presented vignette is analyzed as a function of experimentally varied degrees of objective provocation. Data for this study come from a survey of seventhgraders interviewed in the classroom context. The following sections provide an overview of GST and outline why self-control should condition the relationship between provocation and violence.

\section{General Strain Theory and the Provocation-Violence Link}

GST states that people engage in violence and other types of crime in order to cope with their negative emotions, such as anger, frustration, and depression, caused by experiencing strain or stressors (Agnew 1992, 2006). Strain refers to events, conditions, or types of relationships that are disliked by individuals: "relationships in which others are not treating the individual as he or she would like to be treated" (Agnew 1992, p. 50). The negative emotions aroused by experiencing strain create pressure for corrective action. Crime is a possible coping response, because it might be useful to reduce or escape from strains, seek revenge against the source of strains, and/or alleviate negative emotions (e.g., through drug use). While GST has received solid empirical support in general (e.g. Mazerolle and Piquero 1997; Mazerolle et al. 2000; Piquero and Sealock 2000; Hay 2003; Broidy 2001), the problems of predicting which individuals are particularly likely to react to strain with delinquency and why some people remain resilient, even when experiencing considerable strain, led Agnew to extend the GST in several respects (Agnew 2001, 2006, 2013; Agnew et al. 2002). This includes, amongst other extensions, the introduction of the idea of domain-specific effects of strain, the distinction between objective and subjective strain and a stronger focus on possible coping resources.

In contrast to early theory formulations, in which Agnew (1992) posited a broad connection between various types of strain and delinquent responses in general, Agnew has now narrowed his perspective in more recent versions of the theory, and clarified which strains are most likely to lead to criminal behavior (Agnew 2001). To the extent that criminal coping is a corrective action, or provides a solution to a particular problematic 
situation, strain should have domain-specific effects and produce links between specific strains and specific crimes, rather than a broad connection of stress to various types of crimes. Therefore, "particular strains may be more conducive to some crimes than others (e.g., victimization may be more conducive to violence than to income-generating crime)" (Agnew 2013, 665). As Felson et al. (2012, p. 350) have pointed out, Agnew has placed greater emphasis on the phenomenon that crimes may serve as instrumental solutions to problems created by particular stressors in more recent theory formulations (e.g., incomegenerating crime as a solution to financial stress, counter-aggression as a way to retain a 'tough' reputation and avoid future victimization). Research has just begun to look into the question of whether stress or strain have domain-specific effects on delinquency, but the results so far support the notion that certain types of stress are more closely related to corresponding types of crime (Felson et al. 2012). The results also support the idea that strain has domain-specific effects, e.g., stress in the family is more closely connected to delinquency in the family, and stress in school is closely connected to problem behavior in school (De Coster and Kort-Butler 2006).

In more recent versions of GST, Agnew also differentiated between subjective and objective strains. Objective strains refer to events or conditions which are "disliked by most members of a given group" (Agnew 2001, p. 320). Physical assault or the death of a loved one may serve as examples of strains which are generally disliked. Agnew (2001, p. 321) defined subjective strain as, "events or conditions that are disliked by the people who are experiencing (or have experienced) them." Subjective strain therefore refers to an individual's personal evaluation of an event or condition. People "are much more likely to engage in crime when they experience strains perceived to be high in magnitude and, frequently, unjust" (Agnew 2013, p. 663, emphasis in original). GST states "that subjective strains should have a larger impact on crime than objective strains" (Agnew 2013, p. 654), as the intensity of the emotional reaction to objective strain is closely linked to the subjective evaluation of the strain.

With the introduction of the concept of subjective strain, Agnew (2001) acknowledged that individuals differ with regard to their sensitivity to certain types of experiences. For example, people who are committed to the code of the street or honor cultures (Anderson 2000; Nisbett and Cohen 1996) may judge seemingly harmless jokes or minor slights as severe "challenges to one's honor or reputation, threats to one's core identity as a 'man' and acts that may expose one to ongoing victimization if ignored" (Agnew 2013, p. 664). Since threats to one's 'manliness' might be judged differently by, for example, members of a street gang compared to people with a weak internalization of traditional gender roles, differences in the judgment of such experiences (subjective strain) might result in different rates of violence above and beyond variations in the experience of objective strain between different groups (Agnew 2001, 322, 325-326).

While Agnew's (2001) introduction of individual differences in the judgment of negative events and experiences allows for better predictions as to which individuals will tend towards delinquent coping (i.e., those who judge the respective experience as severe), at the same time it makes separating subjective strain from the associated emotional response problematic. While conceptually the emotional reaction to subjective strain should be a distinct entity from the (cognitive) evaluation of the event or experience in question, in reality, the emotional reaction to strain (i.e., how an individual 'feels' about the event) is closely tied to its cognitive evaluation. Several experimental results on preferences, attitudes and impression formation show that affective reactions can occur without extensive perceptual and cognitive encoding. Instead, affective reactions to stimuli are often the very first reactions of the organism and they are made with greater confidence than cognitive 
judgements (Zajonc 1980). Schwarz and Clore (1988) also demonstrated that, when forming judgments, individuals often use a 'How do I feel about it?' heuristic and incorporate their feelings towards an object into their evaluation. Agnew (2013, p. 656) also stated that the "emotional reaction is primarily a function of the subjective evaluation of the strain" and that "emotions may have feedback effects on the subjective evaluation of the strain" (Agnew 2013, p. 656, emphasis added). However, while it may be difficult to empirically disentangle subjective strain from its emotional 'response', it should at least be possible to infer the subjective evaluation of a stressor from the amount of negative emotions an event or experience induces.

Most research so far has exclusively relied on objective measures of strain, assuming that those are also subjectively disliked by individuals (and remaining this assumption untested). "(I)t is quite rare to ask about the perceived magnitude and injustice of the strain" (Agnew 2013, p. 665). The few studies which directly compared the effects of objective and subjective measures of strain yielded mixed results: while according to Froggio and Agnew (2007), strains that are rated as more severe are more likely to be associated with crime than those rated as less severe, Botchkovar et al. (2009) and Lin and Mieczkowski (2011) did not replicate this finding.

Interpersonal provocation should be an especially interesting example of a specific type of strain that is likely to evoke a particular type of delinquent behavior. At the same time, the link between provocation and violence should be a phenomenon which profits from taking individual differences in sensitivity to strain into account. Strains that involve a personal attack, provocation or affront should be particularly likely to evoke aggressive behavior and violence. "The main type of predicament that leads to coercion is a perceived intentional attack by another person. When people believe that their identities have been attacked, they often experience a loss of status and power, which is accompanied by humiliation" (Tedeschi and Felson 1994, p. 256). Provocation by others has been found to be one of the most important precursors of aggression and violence (Anderson and Bushman 2002, p. 37; Agnew 2006, p. 30). When offenders are asked the reason for their violent actions, having been provoked and having experienced a threat to one's identity or status are by far the most frequent explanations (Agnew 1990; Wilkinson 2002). Provocations include, for example, "insults, slights, other forms of verbal aggression, physical aggression, interference with one's attempts to attain an important goal" (Anderson and Bushman 2002, p. 37). Aggression or violence is often effective in restoring justice after provocations or affronts, and in saving face by lowering the status of the provoking person (Tedeschi and Felson 1994). The anger typically generated by interpersonal provocations (Denson et al. 2011b) should also strongly predispose an individual toward aggressive and violent reactions (Agnew 2006, 2013). Since individuals differ with respect to which identities are salient and important to them (Stryker and Burke 2000), a threat to one's esteem, identity or status may consist of very diverse acts and should be strongly dependent on an individual's personal or group identity. While a provocation in an academic setting may consist of a rude comment about one's abilities or intelligence (DeWall et al. 2007; Denson et al. 2011a), a provocation among street youths might involve maintaining eye contact for too long or bumping into someone (Anderson 2000; Wilkinson 2002; Tertilt 1996). Therefore, the subjective evaluation of an event as a (severe) provocation (subjective strain) can be expected to have more pronounced effects on violence and aggression than an objective measure of provocation. 


\section{Coping Resources in the Provocation-Violence Link: The Role of Self- Control and Risk-Affinity}

When experiencing an intentional affront or provocation, getting angry and having aggressive impulses should be a 'natural' and spontaneous response. However, most individuals do not turn their aggressive impulses into action most of the time. "(I)ndividuals are typically motivated to regulate angry thoughts, feelings, and aggressive behavior" (Denson et al. 2011b, p. 850) because, in the modern world, the display of anger and engagement in aggressive behavior is associated with negative consequences. These include "social disapproval, moral stigma, and legal difficulties" (Denson et al. 2011b, p. 850). Refraining from turning aggressive impulses into action requires impulse control and considering the possible negative consequences of one's actions. Since not all people are able to take into account the negative consequences of aggression, the failure to regulate angry emotions and reacting aggressively to provocation can be regarded as a failure of self-control (Denson et al. 2011b, p. 851; DeWall et al. 2007). Self-control should accordingly be an important coping resource with respect to the provocationviolence link. Psychological research demonstrates that anger regulation, rather than reacting aggressively to provocation, needs and depletes one's self-regulatory capacity (Denson et al. 2011b; DeWall et al. 2007). Conversely, however, low self-control does not seem to increase aggression per se: a depleted capacity for self-regulation increases aggressive responses to an insulting provocation, but participants with such depleted capacity would not behave aggressively in the absence of an esteem-threatening provocation (DeWall et al. 2007), underlining the interplay of a situational stressor (provocation) and low self-control in the evocation of aggression and violence.

In criminology, research routinely uses measures of self-control with subdimensions that are unrelated to self-control's underlying mechanism of being able to control one's impulses and to take into account delayed (negative) consequences of actions. The most famous example is the self-control scale by Grasmick et al. (1993). This scale was developed based on statements about the 'elements of self-control' in Gottfredson and Hirschi's (1990) prominent General Theory of Crime (GTC, also known as self-control theory). However, Gottfredson and Hirschi (1990) used the term 'self-control' in order to "refer to a loose amalgam that seems to include all individual difference factors that might be associated with crime" (Felson and Osgood 2008, p. 160-161). According to them, individuals with low self-control can be characterized as "impulsive, insensitive, physical (as opposed to mental), risk-taking, short-sighted, and nonverbal" (Gottfredson and Hirschi 1990, p. 90). Apart from being largely unrelated to the core underlying mechanism of selfcontrol, this list of characteristics corresponds with different personality traits of the fivefactor model of personality (FFM, see Digman 1990 for a review), which have been shown to be uncorrelated. This casts doubts on the unidimensionality as well as the construct validity of the Grasmick-scale or similar measures of self-control (Marcus 2004; Romero et al. 2003; Hirschi 2004; Piquero 2008). Measures of low self-control such as the scale by Grasmick et al. (1993) therefore remain highly controversial (Hirschi and Gottfredson 1993; Marcus 2003, 2004; Piquero 2008). ${ }^{1}$

\footnotetext{
${ }_{1}$ It should be noted that Hirschi and Gottfredson are strongly opposed to self-control measures such as the Grasmick-scale. Partly in response to the frequent application of the Grasmick-scale when testing propositions of the GTC, Hirschi (2004) admitted that incorporating statements about 'the elements of selfcontrol' in the GTC was a severe mistake and borne out of "a moment of madness" (Hirschi 2004, 541). Also, both authors of self-control theory have repeatedly emphasized that low self-control is defined as the
} 
Self-control measures such as the scale by Grasmick et al. (1993) also combine impulsivity and risk-affinity, although a growing body of research suggest that they refer to different concepts and mechanisms, and that both are uniquely consequential for crime (Ksinan et al. 2014; Burt et al. 2014; Burt and Simons 2013; Schulz 2014). According to the dual-system model by Steinberg et al. (2008), impulsivity and risk-affinity belong to different neurobiological subsystems with underpinnings in different brain regions: the socio-emotional system is seen as responsible for reward-seeking behavior, such as seeking out strong emotional experiences. Risk-affinity can be regarded as a subdimension of such sensation-seeking (Zuckerman 2009). The cognitive control system is related to impulse control and the capacity to reflect on the potential costs of decision-making. Steinberg et al. (2008) point out that impulsivity and risk-affinity may come together in the same persons (i.e. "impulsive risk-takers", Burt et al. 2014, p. 457), but they constitute different behavioral tendencies belonging to different subdimensions of the dual-systems model: "Impulsivity refers to a lack of self-control or deficiencies in response inhibition; it leads to hasty, unplanned behavior. Sensation-seeking, in contrast, refers to the tendency to seek out novel, varied, and highly stimulating experiences, and the willingness to take risks in order to attain them. Not all impulsivity leads to stimulating or even rewarding experiences (e.g., impulsively deciding to end a friendship), and not all sensation-seeking is done impulsively (e.g., purchasing advance tickets to ride a roller coaster or sky dive)" (Steinberg et al. 2008, 1765, emphasis and references dropped).

Focusing on the relationship between provocation and violence, low self-control/impulsivity and risk-affinity should increase the likelihood of a violent reaction to provocation for different reasons (Burt and Simons 2013; Felson and Osgood 2008). Self-control and risk-aversion should therefore constitute different coping resources. As outlined above, low self-control/impulsivity would increase the likelihood of violence because individuals are unable to override their aggressive impulses and make rash and unreflected decisions to react violently. In other words, "they do things they do not really want to do" (Felson and Osgood 2008, p. 162, emphasis added), or which they might regret afterwards, but they cannot stop themselves from doing them. The driving force behind self-control as a coping resource is therefore inhibition. Risk-affinity instead refers to a different aspect of the decision-making process: risk-seekers find violence and other criminal activities more rewarding or, at least, they tend to be less anxious about the potential consequences than risk-averse individuals (Felson and Osgood 2008, p. 165). Risk-affinity could foster violent reactions to provocation because risk-affine individuals should be less scared to counterattack a perceived aggressor, or might even enjoy the thrill of a counterattack. The process underlying risk-aversion as a coping resource is therefore a matter of differential motivation. While both traits can be expected to be relevant for coping with provocation, selfcontrol probably has stronger effects, while differences in motivational factors, such as risk-affinity or fearlessness, should be less important: Felson and Osgood (2008, p. 168) stated that risk-affinity, or the desire for thrills, "should provide more of an incentive for predatory violence than dispute-related violence" because "(p)redatory offenders may enjoy a certain degree of physical danger or the risk of getting caught by the police. Selfcontrol may play a greater role in dispute-related violence- these are the crimes of passion where adversaries lose their temper."

Footnote 1 continued

tendency to act on impulse and to neglect long-term costs in decision-making (Hirschi 1995, 2008; Gottfredson 2011), which overlaps with definitions of the constructs of impulsivity or trait self-control in the field of psychology (e.g. Patton et al. 1995; Buss 2012; Tangney et al. 2004). 
Recent versions of GST would also predict that self-control or individual constraint moderates the impact of strain on delinquency (Agnew 2006; Agnew et al. 2002). However, Agnew's conceptualization of self-control or constraint seems to be even broader and contains yet other 'elements' than that introduced by Gottfredson and Hirschi (1990) and operationalized by Grasmick et al. (1993). This can easily be seen from the following quote: "(I)ndividuals [low in constraint] are impulsive, are risk-taking/sensation-seeking, reject conventional social norms, and are unconcerned with the feelings or rights of others" (Agnew et al. 2002, p. 46).

So far, empirical tests have yielded strongly mixed results with regard to the question whether self-control serves as a coping resource in the strain-delinquency relationship: some studies found support for an interaction between self-control and strain in the prediction of delinquency (Moon et al. 2012; Agnew et al. 2002; Hay and Meldrum 2010; Mazerolle and Maahs 2000; Baron 2009; Turanovic and Pratt 2013), but often studies did not find consistent evidence for such an effect (Peter et al. 2003; Cheung and Cheung 2010; Botchkovar et al. 2009; Ellwanger and Pratt 2014; Hay and Evans 2006; Stogner and Gibson 2010; Jang and Rhodes 2012). One reason might be the widespread use of selfcontrol measures such as the scale by Grasmick et al. (1993). Previous research has often shown that the six components of the Grasmick-scale had differential predictive powers with regard to certain delinquent behaviors (Arneklev et al. 1993; Wood et al. 1993; Longshore et al. 1996; Piquero and Rosay 1998; Delisi et al. 2003; Bornewasser et al. 2007; Conner et al. 2009; Ward et al. 2014). When self-control is treated as unidimensional these differential relationships are obscured. However, if the subdimensions are related to delinquent behaviors for different reasons and have different underlying mechanisms, it can be expected that the involved traits also differ with regard to their role in the conditioning process. Applied to the question of whether self-control/impulsivity moderates the provocation-violence link, it should be more difficult to unravel an existing conditioning effect of self-control if the applied measure combines it with characteristics that are unrelated to self-control in a narrower sense and its functioning in the coping process (e.g. with a preference for physical activities or self-centeredness). Furthermore, as explained above, different personal characteristics, such as impulsivity and risk-affinity (both of which are subdimensions of the Grasmick-scale) could condition the reaction to strain, but for different reasons. If both are combined in a composite index, a sound understanding of the processes or mechanisms involved in the conditioning process, in other words, why people differ in their reaction to provocation, is made impossible.

In order to better understand why some individuals seem to be more tolerant of the experience of strain than others and are able to cope in a non-delinquent manner, unidimensional measures with good content validity are vital. It should be noted that this argument stands in contrast to the recent advice by Agnew (2013) on how to test for factors conditioning the reaction to strain. Agnew (2013) suggested that researchers should investigate sets of characteristics "that together create a strong propensity for criminal coping" (Agnew 2013, p. 653) and criticized research that "considers each characteristic in isolation, with other relevant characteristics controlled" (Agnew 2013, p. 662). If combining a host of conditioning variables into one scale is not possible, Agnew advised survey researchers to "measure the individual's standing on factors that serve as a 'marker' for a host of conditioning variables, with such markers including gang membership, living on the street, and perhaps designation as a 'life-course-persistent' offender" (Agnew 2013, p. 665). Yet, while it may enhance the ability to predict maladaptive coping if the overall standing on a host of well-known conditioning factors is considered, it does not improve the understanding of the coping process. Also, up until now, research has failed to identify 
clear and unquestioned conditioning variables which could be summarized as a factor creating a 'propensity for criminal coping.' On the contrary, research on the factors that condition the effect of strain has so far produced mixed results, at best (Agnew 2013, p. 658), and empirical evidence increasingly suggests that aggregating potentially distinct decision tendencies into one overarching construct of 'criminal propensity' or 'low selfcontrol' may obscure, rather than clarify, a sound understanding of the processes leading to criminal behavior (see also Pogarsky 2007, p. 73; Schulz 2014).

The current strategy is, accordingly, to refrain from using a self-control measure which combines different subdimensions of 'criminal propensity,' but instead to apply measures of two decision-making tendencies which seem to be central to delinquent behavior: low self-control/impulsivity and risk-affinity. Although the results of the moderator effects of self-control are strongly mixed, studies that match types of strain to corresponding types of problem behavior (e.g., victimization to violence) and that capture 'low self-control' using items on impulsivity, sensation-seeking, and/or temper, tend to be more likely to find an interaction between their measures and strain (Baron 2009; Hay and Meldrum 2010; Jang and Rhodes 2012; Moon et al. 2012; Turanovic and Pratt 2013). Studies that do not find consistent evidence of an interaction between self-control and strain tend to use the selfcontrol scale developed by Grasmick et al. (1993) or similar measures (Botchkovar et al. 2009; Cheung and Cheung 2010; Ellwanger and Pratt 2014), and/or fail to match strain with corresponding types of delinquency (Botchkovar et al. 2009; Cheung and Cheung 2010; Stogner and Gibson 2010).

\section{Present Study}

The current study advances knowledge on whether self-control conditions the reaction to strain by addressing three problems simultaneously.

1. It builds on previous research that demonstrates that, when predicting delinquent coping with strain, research benefits from taking into account the nature of the stressor and the reason behind a certain coping strategy (Felson et al. 2012). This study therefore analyzes whether self-control enables an individual to keep calm and not react violently when faced with a type of strain likely to evoke an aggressive response: interpersonal provocation. It can be expected that the relationship between provocation and violence is stronger if self-control is low and weaker if self-control is high.

2. This study focuses on self-control as a coping resource, while using an appropriate measure that adequately captures its underlying mechanism of restraining impulses and taking long-term costs into account in decision-making. In the presence of angerinducing provocation, self-control should enable individuals to suppress their anger and aggressive impulses and to take into account the long-term costs of aggression and violence. In the absence of provocation, the effect of low self-control on (disputerelated forms of) violence and aggression should be considerably weaker. The conditioning effects of low self-control/impulsivity are contrasted with those of riskaffinity. It could be expected that risk-affinity also amplifies the relationship between provocation and violence, but for a different reason than low self-control: risk-affine individuals should be less anxious to attack a provoking actor or might even enjoy the thrill of a (counter-)attack. However, self-control should be more important than riskaversion in dispute-related violence, as in the case of provocation (Felson and Osgood 2008). 


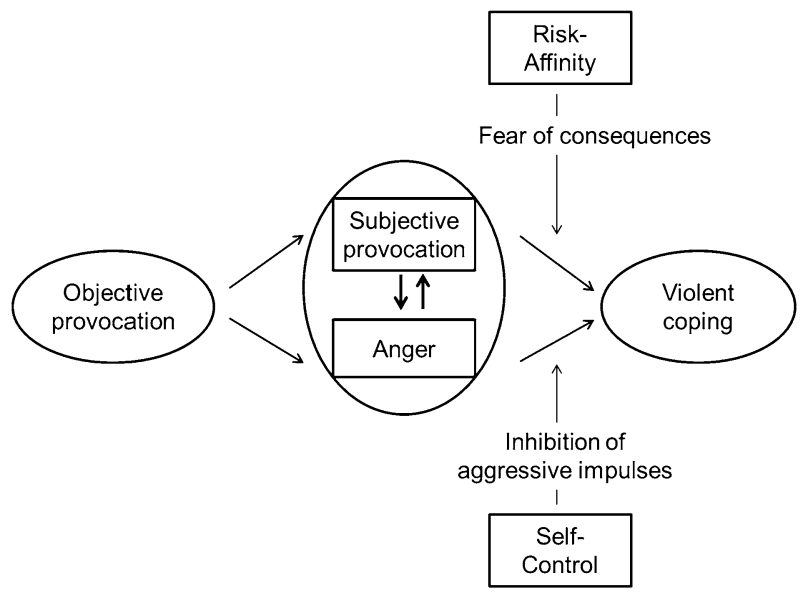

Figure inspired by Agnew (2013, p. 655)

Fig. 1 Causal diagram of processes under study

3. Strains that are subjectively evaluated as high in magnitude should lead to stronger emotional responses and have a larger impact on crime than objective strains (Agnew 2013, p. 654; Froggio and Agnew 2007). Without strong aggressive impulses, there should also be no need for self-control as a coping resource. Conditioning effects should therefore also be more easily revealed when using subjective measures of provocation rather than objective measures.

Figure 1 provides an illustration of the whole process under study.

\section{Data}

Analyses are based on the first wave of data from the project 'Friendship and Violence in Adolescence,' which is a prospective longitudinal study of seventh-graders in five cities in the Ruhr that started in 2013. The Ruhr, located in Western Germany, is the largest urban agglomeration of cities in Germany and is characterized by the downturn in coal and steel production, a high population density, and high levels of unemployment. A large proportion of the population has a foreign background. Apart from special-needs schools and the schools of the highest type (German 'Gymnasium'), all schools from the five cities were asked to participate in the survey with their entire seventh grade. Only five of the 44 schools declined to participate, and $79 \%$ of the seventh-graders at the participating schools took part in the study $(n=2635)$. Participation was voluntary for the students and required parental consent. In order to maximize privacy, interviews were collected as computeradministered self-interviews (CASI). In order to counteract language and illiteracy problems, students could also listen to questions and answer options via headphones. Following data cleaning and the elimination of incomplete or otherwise unusable questionnaires, a total working sample of 2608 cases was generated (52.6\% boys; average age 13.1 years, $\mathrm{SD}=0.62$ ). 


\section{Measures}

\section{Subjective Provocation}

The questionnaire contained an eight-item measure of subjective sensitivity to provocation that assesses the amount of frustration felt when encountering provocations of varying degrees. Respondents were provided with eight short descriptions of situations and asked whether, and how much, they would get frustrated in this situation. Answer options were 1 ('That doesn't bother me'), 2 ('I am a little annoyed by this'), and 3 ('That really enrages me'). The scenarios were selected after extensive cognitive pretesting with youths of similar age as the target respondents. The situational descriptions were purposely selected to represent everyday social interactions for youths from this age group. It was ensured that the encounters described in the selected scenarios varied from rather mild and ambiguous provocations, such as 'Someone asks you to take your shoes off the seat on a train', to severe slights, such as 'Someone makes jokes about your family.' The more items were answered affirmatively, the greater the sensitivity should be to encounters which might be considered as a provocation (subjective strain). Also, respondents who state that they would react with much anger and frustration should subjectively feel provoked more intensely than respondents who state that they would not be bothered by these experiences (the item wording and basic descriptives can be found in Table 3 in the Appendix). The reliability of the overall scale is good, with a Cronbach's alpha of 0.69 . Removing any of the items would lower Cronbach's alpha. The overall measure of subjective provocation is computed as the arithmetic mean of the answers to the eight items. For analysis purposes, the scale was z-standardized.

Readers may note that this scale might resemble some previous approaches to measuring situational or state anger (Capowich et al. 2001; Jang and Johnson 2003; Moon et al. 2009; Broidy 2001). As mentioned above, the complication of separating strain theory's core action-guiding construct of anger from strain is partly linked to Agnew's (2001) introduction of a subjective or judgmental component to the experience of strain, because affective states and cognitive judgments of an event or an experience as aversive should mingle and are hard to separate in real life (Zajonc 1980; Schwarz and Clore 1988). I perceive the important distinction between measures of situational anger and the present approach to measure subjective sensitivity to provocation is that the present measurement assesses the proclivity to get frustrated across different situations which might or might not be considered as provocations by different actors. Therefore, a person with a high value on the present measure should get frustrated by very different encounters and therefore consider more situations as straining, whereas a person with low values sees the majority of encounters as unproblematic. Situational measures of anger, instead, rather tend to assess how often a person got angry (after experiencing strain) in a certain reference period or, when applying scenario techniques, ask for the probable amount of anger felt after presenting only one scenario to the respondent. Accordingly, instead of measuring angry reactions (which measures of state anger aim at) the present measure focuses on individual differences in situational determinants of angry reactions (also see Spielberger et al. 1983; Spielberger et al. 1995 for different facets of anger/hostility measurements). Therefore, while the present measure of sensitivity to provocation is not the most direct measurement (i.e., because of the high cognitive burden it was not asked, 'which of the following situations would you rate as a provocation?'), the amount of frustration felt in response to the short situational descriptions should closely mirror their subjective evaluation as 
aversive (for a similar approach to the measurement of subjective strain see Ellwanger and Pratt 2014). Therefore, the underlying assumption is that, if respondents indicate that they would not get angry when encountering any of the presented scenarios, they should not feel provoked either. $^{2}$

\section{Low Self-Control/Impulsivity and Risk-Affinity}

The questionnaire contained five items which can be regarded as indicators of impulsivity and two items for risk-affinity. Response options ranged from 1 ('disagree strongly') to 5 ('agree strongly'). In order to ensure unidimensional scale constructions, a series of confirmatory factor analyses were estimated. The results implied that one of the impulsivity items should be dropped from further analysis. ${ }^{3}$ The item wording of the remaining four items was as follows: 'I often say things I haven't thought about enough'; 'I get bored easily'; 'I often act on the spur of the moment without stopping to think', and 'Usually I am able to control myself well. ${ }^{4}$ The scale reliability is below values which are generally regarded as acceptable in psychometric research and psychological testing (Cronbach's alpha $=0.50$ ). However, it is in the expected range for short scales in survey research (Diekmann 2010, p. 254). ${ }^{5}$ The item wording of the two risk-affinity items was 'Sometimes I will take a risk just for the fun of it', and 'I sometimes find it exciting to do things that may be dangerous.' Both items are highly correlated (Pearson's $r=0.64$ ), yielding a Cronbach's alpha of 0.77 when both are combined in a scale. Scales for risk-affinity and low self-control/impulsivity were constructed by computing the arithmetic mean of the

\footnotetext{
${ }^{2}$ Note that in psychological research, the amount of anger felt is also used as a manipulation check for experimentally induced levels of provocation (e.g. Denson et al., 2011b).

3 A first model, specifying one common factor for all seven items did not achieve a satisfactory model fit $\left(\chi^{2}=603.43 ; d f=14 ;\right.$ RMSEA $=0.129 ; \mathrm{CFI}=0.82 ;$ SRMR $\left.=0.073 ; \mathrm{BIC}=53,165.92\right)$. Modification indices indicated that the model could be improved by allowing for correlated error terms between the items on impulsivity, as well as between those on risk-affinity, implying that items on each trait share variance which is not explained by one common factor. A second model with one latent variable for impulsivity and one for risk-affinity achieved a markedly better model fit $\left(\chi^{2}=284.40 ; d f=13\right.$; RMSEA $=0.091$; $\mathrm{CFI}=0.92 ; \mathrm{SRMR}=0.050 ; \mathrm{BIC}=52,854.73)$. Nevertheless, the model fit was still suboptimal. In a next step, one impulsivity item for which modification indices indicated a substantial error correlation with an item of the risk affinity dimension was dropped from further analysis. This model achieves a satisfactory model fit $\left(\chi^{2}=48.85 ; d f=8 ;\right.$ RMSEA $=0.045$; CFI $=0.982 ;$ SRMR $\left.=0.028 ; \mathrm{BIC}=45,612.98\right)$. Both risk-affinity items had factor loadings of at least 0.78 . All but one of the impulsivity items had factor loadings of at least 0.49 . Closer inspection of this item revealed that it was the only reverse coded item, formulated in the direction of low impulsivity/high self-control ('Usually I am able to control myself well'). Since this item should actually meet the core of self-control, deleting it from the scale would sacrifice better content validity for a further increase in model fit. It was therefore decided to keep this item in the impulsivity scale.

4 Items on the tendency to get bored are sometimes included in measures of risk-affinity. Theoretically, getting bored and distracted easily is a facet of both impulsivity and risk-affinity. Buss (2012, p. 91) stated that "impulsive people tend to become bored easily, which is also a characteristic of sensation seekers. This overlap poses problem for personality researchers, who reasonably prefer neater, sharper distinctions between traits. However, both impulsives and sensation seekers do become bored easily (...). This is not a unique case because other personality traits overlap, such as dominance and self-esteem." In the present case, the item on boredom had high loadings on the impulsivity factor without any indication of a cross loading on the risk-affinity factor. Therefore, it was decided to keep this item in the impulsivity scale. Deleting this item from the scale does not substantially alter results. Results are available upon request.

5 Note that keeping the average inter-item correlation of 0.20 constant, Cronbach's alpha would reach a value of 0.75 by merely increasing the number of items to 12 .
} 
answers to the respective items. For analysis purposes, both measures were also z-standardized. The correlation between risk-affinity and impulsivity is $0.39(p<0.001)$.

\section{Past Violent Behavior}

Respondents were asked about the frequency of their involvement in assault within the previous 12 months. Specifically, they were asked whether they had assaulted with injury using a weapon, and whether they had assaulted with injury without using a weapon. ${ }^{6}$ Given that most students did not commit acts of violence, and that those who did committed very few violent acts, a measure of the prevalence of violence within the past 12 months was constructed. Respondents who reported having committed assault were coded 1 and those who did not were coded 0 . Overall, 17.7 percent of the students reported having committed an assault within the 12 months before the interview.

\section{Scenario Design and Experimental Manipulations}

In order to research the reaction to objective provocations, respondents were also presented with a scenario describing a situation with the opportunity to react violently. The scenario was adapted from a scenario used in the Peterborough Adolescent and Young Adult Development Study (PADS+, see Wikström et al. 2012). Selected scenario conditions were experimentally varied across respondents, including the level of provocation by another scenario character. Male respondents were presented scenarios with male characters, and female respondents with female characters. The following is an example of the scenarios used:

Katrin (Martin) is waiting for the bus at a bus stop late in the evening. She (he) is listening to her (his) iPod. Suddenly a girl (boy) who walks by pushes her (him) so she (he) drops her (his) iPod to the ground and it breaks. Katrin (Martin) asks the girl (boy): "Why did you push me?" Then the girl (boy) pushes her (him) again. There are two peers standing nearby, curiously watching the situation. There are two police officers walking on the other side of the street. Imagine you were Katrin (Martin) and had been pushed. Would you push or hit the other girl (boy)?

Answer options were on a four-point scale: 0 ('Yes, very likely'), 1 ('Probably yes'), 2 ('Probably no'), and 3 ('No, very unlikely'). To represent the projected likelihood of acting violently, answers were reverse coded. Experimental variations were the time of day (late in the evening/around noon), the presence of third parties (whether there was nobody else present, police officers nearby, peers nearby, or both nearby), and the intensity of provocation by the other scenario character. In the low-intensity provocation scenario, the girl/boy only tells the protagonist to turn down the music. In the moderate-intensity

\footnotetext{
${ }^{6}$ Respondents were asked the following series of questions for assault without using a weapon: 'Have you ever hit or kicked someone on purpose resulting in injury (for example, such that he/she bled or had bruises)? But without using a weapon or some other object. Do not count events in combat sports.' If respondents indicated that they did, they were asked 'Within the past 12 months, have you hit or kicked someone on purpose resulting in injury?' Respondents who again indicated that they did, were then asked about the frequency within the past 12 months. The following questions were asked for assault using a weapon: 'Have you ever purposely hurt or tried to hurt someone with an object or a weapon (for example a chain, a knife or teargas)?', and 'Within the past 12 months, have you purposely hurt or tried to hurt someone with an object or a weapon (for example a chain, a knife or teargas)?' Respondents indicating assault with a weapon within the past 12 months were also asked about the frequency within the past 12 months.
} 
version, the other character pushes the protagonist and ignores the protagonist after being asked why. In the high-intensity version, the other character pushes the protagonist twice and the iPod breaks (as in the example above). There were a total of 48 versions of the scenario (24 experimental variations for each gender). Since the intensity of provocation in the scenario was experimentally varied across respondents, the projected reaction to it can be regarded as an adequate assessment of the projected reaction to objective provocation, the type of strain studied here.

In order to differentiate more clearly between respondents who tend toward violence and those who do not, the projected violence measure was dichotomized $(1=$ 'Yes, very likely' and 'Probably yes'; $0=$ 'No, very unlikely' and 'Probably no'). This also allows for better comparability between the analyses on projected violence and the analyses on the prevalence of violence within the past 12 months. Two-thirds of respondents $(66.7 \%)$ stated they would not react with violence in the presented scenario, and one-third tended toward a violent reaction.

\section{Control Variables}

The analyses control for gender $(1=$ male; $0=$ female $)$ and age of the respondents. Age is centered at its mean when entered into the regression analysis.

\section{Analytic Strategy}

When analyzing non-normally distributed variables, such as measures of crime and delinquency, advanced regression techniques for count data or regression techniques for binary outcomes (e.g., when analyzing the prevalence of offending) are routinely used (but see Mazerolle and Maahs 2000). However, researchers often overlook the problem that, when applying regression techniques to non-linear dependent variables such as probit or logistic regressions, testing for an interaction between two variables to predict the probability of a certain outcome cannot be evaluated by looking merely at the sign, magnitude, or statistical significance of the coefficient of an included product term between the variables assumed to interact. First, non-linear models contain model-inherent interaction terms, since the effect of a change in any independent variable on the probability of the dependent variable will depend on the values of all of the other independent variables included in the model (Nagler 1994; Ai and Norton 2003). Since coefficients from logistic regression (i.e., logits) are non-linearly related to the predicted probabilities of the dependent variable - with effects highest at a predicted probability of around 0.5 and smallest as the predicted probabilities approach 0 and 1 -this dependence on the other variables in the model is present even if the other variables are unrelated to the independent variable of interest (Mood 2010). Furthermore, in contrast to linear regression, the residual variance in logistic regression is fixed; therefore a difference in coefficients between groups may also result from differences in unobserved variance only (Allison 1999; Auspurg and Hinz 2011). This also pertains to differences between groups within the same logistic regression model, as is the case in the estimation of interaction effects (Mood 2010). Drawing conclusions about the presence or absence of conditioning effects by looking only at the size or significance of the coefficient of an included product term between two variables in a non-linear model may, accordingly, be very misleading. 
The application of a linear probability model (LPM) is an appropriate solution to the problem of estimating interaction effects when the dependent variable is binary (Mood 2010). The LPM applies the multiple linear regression model to binary dependent variables, as shown in Eq. (1):

$$
\mathrm{P}(\mathrm{y}=1 \mid \mathbf{x})=\beta_{0}+\beta_{1} \mathrm{x}_{1}+\cdots+\beta_{\mathrm{k}} \mathrm{x}_{\mathrm{k}}
$$

The LPM estimates the probability of the outcome $\mathrm{y}=1$ as a linear function of $\mathrm{x}_{\mathrm{k}}$. The slope coefficient $\beta_{\mathrm{k}}$ measures the predicted change in the probability of $\mathrm{y}=1$ when $\mathrm{x}_{\mathrm{k}}$ increases by one unit, and the intercept $\beta_{0}$ is the predicted probability of $\mathrm{y}=1$ if all $\mathrm{x}_{\mathrm{k}}$ are set to zero (Wooldridge 2013). In the case of linear regression, coefficients are easily comparable across models and groups. The results from the LPM can be directly interpreted in terms of probability changes (Mood 2010; Wooldridge 2013), and interaction effects can easily be studied by including a product term between the measures of interest in the linear regression equation. However, while the use of LPMs is common in econometrics, they are seldom used in other disciplines (Mood 2010, p. 78). Three general arguments against their use are pointed out: the possibility of out-of-range predictions, heteroscedastic error terms, and the misspecified functional form of the underlying model (see Mood 2010). However, unrealistic predicted values also often occur in linear regression with non-binary outcomes (e.g., in the case of predicting a negative salary), which does not necessarily suggest they should not be used on binary outcomes per se. Also, the misspecification of the functional form can be neglected in certain cases, for example, when there is no interest in the nonlinearity of the relationship itself or in the marginal effect of a variable at a certain point of the probability distribution, but in (differences in) average effect estimates and the sign and significance of relationships (Mood 2010), as is the case with regard to the current research question. In fact, "the LPM effect estimates are unbiased and consistent estimates of a variable's average effect on $\mathrm{P}(\mathrm{y}=1)$ " (Mood 2010, p. 78, emphasis added). Heteroscedasticity seems to be more important, as it may affect the estimated standard errors. However, Hellevik (2009) showed in a recent simulation study that linear and logistic significance tests yield almost identical results, and their $p$ values differ by $<0.005$ in the clear majority of cases $(90 \%)$. Since the present study focuses on the analysis of conditioning effects, the LPM is used. ${ }^{7}$ In all regression models, cluster-robust standard errors account for the possibility that students from the same class might be more similar to each other than to students from different classes.

\footnotetext{
${ }^{7}$ A possible alternative would be to use logistic regressions and to compare the average marginal effects (AMEs) of the independent variables at different levels of the conditioning variable (see e.g. Moon et al. 2012), and to test for significant differences in the AMEs across the separate models (see Auspurg and Hinz 2011). Grouping a continuous measure such as the present measure of low self-control, however, also leads to a considerable loss of information. Robustness checks demonstrate that for the present research question, this approach would largely lead to the same conclusions (see Table 4 in the Appendix for the effects of subjective provocation at different levels of self-control). In order to illustrate the problem of merely evaluating conditioning effects by including a product term between two variables in logistic regressions, I also report the results of a logistic regression on the full sample including a product term between low selfcontrol and subjective provocation.
} 


\section{Results}

A first model regresses the prevalence of violence within the past 12 months on measures of subjective sensitivity to provocation, low self-control/impulsivity and risk-affinity (Table 1). Low self-control and risk-affinity each independently increase the probability of violence, while risk-affinity has stronger effects: while an increase in risk-affinity by one standard deviation increases the probability of violence by ten percentage points, an increase by one standard deviation in low self-control/impulsivity increases the probability of violence by only four percentage points. Subjective sensitivity to provocation has an effect of similar size as low self-control. The second and third model assess the individual conditioning effects of low self-control and risk-affinity. Both models produce almost identical results: Both impulsivity and risk-affinity seem to condition the relationship between subjective provocation and violence and the estimates of the included interaction terms are of equal size and significant $(p<0.01)$. Model 4 includes both product terms simultaneously. The results of this model indicate that self-control and risk-affinity each independently condition the link between provocation and self-control. This implies that both traits make violent reactions to provocation more likely, but for different reasons. Furthermore, self-control seems to be a more important coping resource for subjective provocation, as the effect size of the product term between risk-affinity and sensitivity to provocation decreases as compared to Model 3, while the interaction effect between impulsivity and subjective provocation remains constant.

Figure 2 displays both interactions graphically. When self-control is highest, subjective sensitivity to provocation does not have an effect on the probability of violence. This implies that individuals with high self-control are able to control their anger and suppress aggressive impulses when they feel provoked. Furthermore, when subjective sensitivity to provocation is minimal, low self-control does not increase the probability of violence. This supports the idea that the effect of low self-control on violence works to a large degree through the higher probability of reacting violently to provocation, stressing the need for a

Table 1 LPM regressions of violence within the past 12 months on subjective provocation: the conditioning effects of self-control and risk-affinity

$* p<0.05, * * p<0.01$;

Standard errors in parentheses

\begin{tabular}{|c|c|c|c|c|}
\hline & (1) & (2) & (3) & (4) \\
\hline Male & $\begin{array}{l}0.04 * * \\
(0.01)\end{array}$ & $\begin{array}{l}0.04 * \\
(0.01)\end{array}$ & $\begin{array}{l}0.04 * \\
(0.01)\end{array}$ & $\begin{array}{l}0.04 * \\
(0.01)\end{array}$ \\
\hline Age, centered & $\begin{array}{l}0.04 * \\
(0.01)\end{array}$ & $\begin{array}{l}0.03 * \\
(0.01)\end{array}$ & $\begin{array}{l}0.03 * \\
(0.01)\end{array}$ & $\begin{array}{l}0.03^{*} \\
(0.01)\end{array}$ \\
\hline Low self-control (LSC) & $\begin{array}{l}0.04 * * \\
(0.01)\end{array}$ & $\begin{array}{l}0.04 * * \\
(0.01)\end{array}$ & $\begin{array}{l}0.04 * * \\
(0.01)\end{array}$ & $\begin{array}{l}0.04 * * \\
(0.01)\end{array}$ \\
\hline Risk-affinity (RA) & $\begin{array}{l}0.10^{* *} \\
(0.01)\end{array}$ & $\begin{array}{l}0.10 * * \\
(0.01)\end{array}$ & $\begin{array}{l}0.10 * * \\
(0.01)\end{array}$ & $\begin{array}{l}0.10^{* * *} \\
(0.01)\end{array}$ \\
\hline Subjective provocation & $\begin{array}{l}0.04 * * \\
(0.01)\end{array}$ & $\begin{array}{l}0.04 * * \\
(0.01)\end{array}$ & $\begin{array}{l}0.04 * * \\
(0.01)\end{array}$ & $\begin{array}{l}0.04 * * \\
(0.01)\end{array}$ \\
\hline $\mathrm{LSC} \times \mathrm{SP}$ & & $\begin{array}{l}0.02 * * \\
(0.01)\end{array}$ & & $\begin{array}{l}0.02 * \\
(0.01)\end{array}$ \\
\hline $\mathrm{RA} \times \mathrm{SP}$ & & & $\begin{array}{l}0.02 * * \\
(0.01)\end{array}$ & $\begin{array}{l}0.01 * \\
(0.01)\end{array}$ \\
\hline Constant & $\begin{array}{l}0.16 * * \\
(0.01)\end{array}$ & $\begin{array}{l}0.15 * * \\
(0.01)\end{array}$ & $\begin{array}{l}0.15 * * \\
(0.01)\end{array}$ & $\begin{array}{l}0.15^{* * *} \\
(0.01)\end{array}$ \\
\hline Observations & 2559 & 2559 & 2559 & 2559 \\
\hline $\mathrm{R}^{2}$ & 0.155 & 0.159 & 0.159 & 0.161 \\
\hline
\end{tabular}



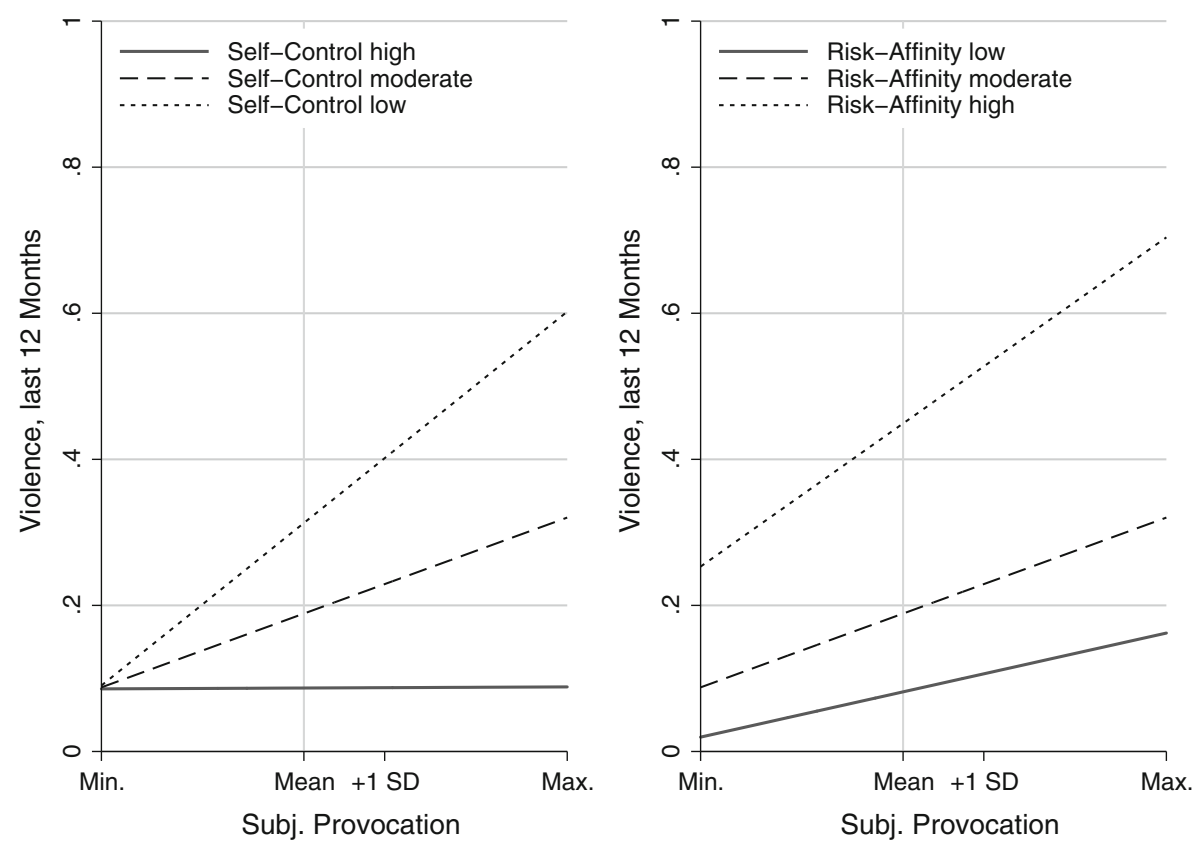

Predicted values based on Model 4. Values of covariates: male, average age (13.1 years), average risk-affinity (left graph) or average self-control (right graph)

Fig. 2 Violence within the last 12 months and subjective provocation by levels of self-control and riskaffinity

situational trigger of a violent reaction of individuals without self-control. Risk-seekers are also more likely to react violently when they feel provoked, compared to risk-averse individuals, but differences in the slope of subjective provocation are less pronounced when compared to differences between individuals with highest and lowest self-control. Also, risk-affinity seems to have an effect on violence above and beyond the probability of reacting violently to provocation, as the proclivity for risk still has an effect on violence when subjective sensitivity to provocation is minimal.

Table 2 shows the results of regressions of the measure of projected violence on experimentally varied degrees of objective provocation within the presented scenario. All models control for effects of other scenario conditions (such as the time of day or the presence of third parties) which are not relevant for the present research question. Model 5 in Table 2 shows that self-control and risk-affinity make projecting a violent reaction in the presented scenario more likely. Both moderate and high levels of objective provocation by the scenario character strongly increase the inclination to act violently compared to the reference category of a low level of provocation. An additional Wald test shows that a high level of provocation strongly increases the inclination to act violently relative to moderate provocation $\left(\mathrm{F}_{(1,121)}=88.7\right.$; Model 5).

Model 6 tests for interactions between low self-control/impulsivity and experimentally varied levels of objective provocation. Only the entered product term between low selfcontrol and a moderate level of objective provocation is significant at conventional levels, implying that individuals with low self-control are more likely to react violently in this 
Table 2 LPM regressions of projected violence (scenario) on objective provocation: the conditioning effects of self-control and risk-affinity

\begin{tabular}{|c|c|c|c|c|}
\hline & $(5)$ & (6) & (7) & (8) \\
\hline Male & $\begin{array}{l}0.11 * * \\
(0.02)\end{array}$ & $\begin{array}{l}0.12 * * \\
(0.02)\end{array}$ & $\begin{array}{l}0.11 * * \\
(0.02)\end{array}$ & $\begin{array}{l}0.12 * * \\
(0.02)\end{array}$ \\
\hline Age, centered & $\begin{array}{l}0.06 * * \\
(0.01)\end{array}$ & $\begin{array}{l}0.06 * * \\
(0.01)\end{array}$ & $\begin{array}{l}0.06 * * \\
(0.01)\end{array}$ & $\begin{array}{l}0.06^{* * *} \\
(0.01)\end{array}$ \\
\hline Low self-control (LSC) & $\begin{array}{l}0.04 * * \\
(0.01)\end{array}$ & $\begin{array}{l}0.02 \\
(0.01)\end{array}$ & $\begin{array}{l}0.04 * * \\
(0.01)\end{array}$ & $\begin{array}{l}0.03 * * \\
(0.01)\end{array}$ \\
\hline Risk-affinity (RA) & $\begin{array}{l}0.10 * * \\
(0.01)\end{array}$ & $\begin{array}{l}0.10 * * \\
(0.01)\end{array}$ & $\begin{array}{l}0.06 * * \\
(0.01)\end{array}$ & $\begin{array}{l}0.06^{* * *} \\
(0.01)\end{array}$ \\
\hline Objective provocation: low (OPL) & Ref. & Ref. & Ref. & Ref. \\
\hline Objective provocation: moderate (OPM) & $\begin{array}{l}0.26^{* * *} \\
(0.02)\end{array}$ & $\begin{array}{l}0.26 * * \\
(0.02)\end{array}$ & $\begin{array}{l}0.26^{* * *} \\
(0.02)\end{array}$ & $\begin{array}{l}0.26^{* * *} \\
(0.02)\end{array}$ \\
\hline Objective provocation: high $(\mathrm{OPH})$ & $\begin{array}{l}0.43 * * \\
(0.02)\end{array}$ & $\begin{array}{l}0.43 * * \\
(0.02)\end{array}$ & $\begin{array}{l}0.43 * * \\
(0.02)\end{array}$ & $\begin{array}{l}0.43 * * \\
(0.02)\end{array}$ \\
\hline $\mathrm{LSC} \times \mathrm{OPM}$ & & $\begin{array}{l}0.05 * * \\
(0.02)\end{array}$ & & $\begin{array}{l}0.03 \\
(0.02)\end{array}$ \\
\hline $\mathrm{LSC} \times \mathrm{OPH}$ & & $\begin{array}{l}0.02 \\
(0.02)\end{array}$ & & $\begin{array}{l}-0.00 \\
(0.02)\end{array}$ \\
\hline $\mathrm{RA} \times \mathrm{OPM}$ & & & $\begin{array}{l}0.07 * * \\
(0.02)\end{array}$ & $\begin{array}{l}0.06^{* * *} \\
(0.02)\end{array}$ \\
\hline $\mathrm{RA} \times \mathrm{OPH}$ & & & $\begin{array}{l}0.05 * * \\
(0.02)\end{array}$ & $\begin{array}{l}0.06^{*} \\
(0.02)\end{array}$ \\
\hline Constant & $\begin{array}{l}0.09 * * \\
(0.02)\end{array}$ & $\begin{array}{l}0.09 * * \\
(0.02)\end{array}$ & $\begin{array}{l}0.09 * * \\
(0.02)\end{array}$ & $\begin{array}{l}0.09 * * \\
(0.02)\end{array}$ \\
\hline Observations & 2564 & 2564 & 2564 & 2564 \\
\hline $\mathrm{R}^{2}$ & 0.245 & 0.247 & 0.249 & 0.250 \\
\hline
\end{tabular}

$* p<0.05$, ** $p<0.01$; Standard errors in parentheses. Models control for effects of other scenario conditions

scenario condition than those with high self-control. The interaction between high objective provocation and low self-control is far from statistical significance. This result might possibly be attributed to the very high level of provocation in this scenario condition, since the protagonist in the presented scenario was pushed twice for no reason and his/her possession was damaged. Overall, 53.1 percent of respondents in this scenario condition state that they would be inclined to act violently. It may be possible that such a strong attack by the other scenario character might be a valid justification for a counterattack or even a 'call' for self-defense. In this case, an aggressive response might be less of a failure of self-control.

Model 7 repeats this analysis with risk-affinity as the moderator of the effects of objective provocation. The interaction effects between risk-affinity and objective provocation are stronger than those between self-control and objective provocation (Model 6). Interestingly, an individual's risk-affinity and fearlessness also further increases his/her inclination to act violently under the condition of a very high level of provocation. Model 8 includes both the interactions between self-control and objective provocation as well as 

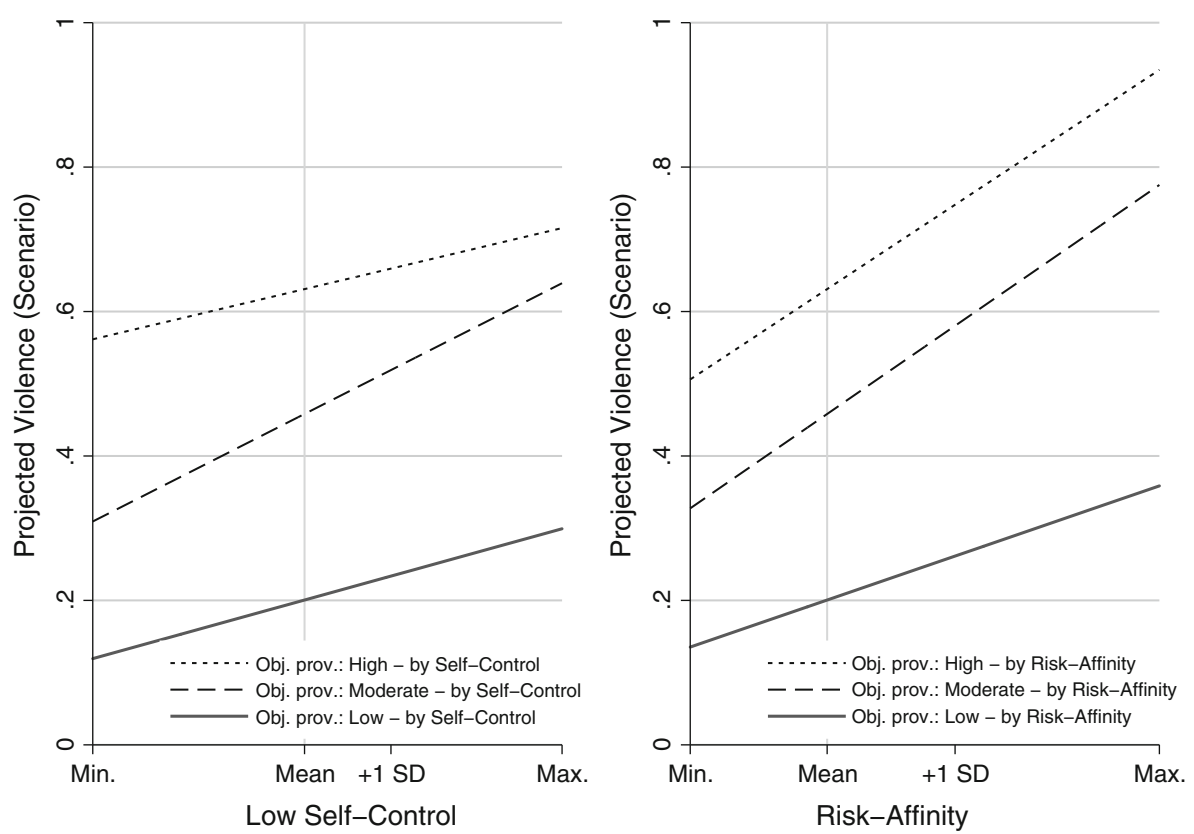

Predicted values based on Model 8. Values of covariates: male, average age (13.1 years), average risk-affinity (left graph) or average self-control (right graph)

Fig. 3 Projected violence and objective provocation by levels of self-control and risk-affinity

those between risk-affinity and objective provocation. Figure 3 depicts the interactions from Model 8 graphically.

The coefficients of the product terms between low self-control and objective provocation decrease, implying that part of the interaction between self-control and objective provocation (Model 6) was probably due to the correlation between self-control and riskaffinity or the fact that impulsivity and risk-affinity sometimes come together in the same people. As a result, the interaction between self-control and moderate provocation is no longer significant in Model 8. Overall, the present analyses find less evidence for a conditioning effect of low self-control when applying an objective measure of provocation instead of a subjective measure. This might indicate that a subjective measure of sensitivity to provocation might be better suited for revealing the actual need for resources for regulating angry aggressive impulses. The interactions between risk-affinity and objective levels of provocation remain of similar size and significant when including the product terms between self-control and objective provocation in the model. The coefficient of the interaction term between risk-affinity and high objective provocation even increases a little when controlling for the conditioning effects of self-control, also speaking for the interpretation that risk-affinity and self-control lead to violent reactions for different reasons and constitute different coping resources. Overall, the pattern of results speaks against the use of composite measures of 'criminal propensity' when trying to understand which individuals are most prone to delinquent coping (and why). 


\section{Discussion}

The aim of the present study was to shed light on the question of whether low self-control conditions the link between strain and delinquency. It did so by addressing three problems simultaneously. First, instead of applying composite measures of different types of strain and a composite measure of 'general delinquency' without paying attention to the reason or mechanism underlying delinquent coping, it considered a specific type of strain that is particularly conducive to violence and matched it with the coping resource that is likely to be invoked in not responding violently to this type of strain: self-control. Second, drawing on recent work which suggests that criminological research could benefit from differentiating between the personality traits of risk-affinity and impulsivity (Burt and Simons 2013; Burt et al. 2014; Ksinan et al. 2014; Schulz 2014; Felson and Osgood 2008), this study contrasted the conditioning effect of low self-control/impulsivity with that of riskaffinity, while using mechanism-congruent measures for both traits. The conditioning processes were analyzed using objective and subjective measures of provocation, because strain that is subjectively perceived as aversive should elicit a stronger need for coping resources. Analyses were based on a large sample of seventh-graders interviewed in the classroom setting in five cities in Western Germany. The used measures comprise an experimental scenario design as well as self-reports of past violent behavior.

The results from the LPMs demonstrate that subjective sensitivity to provocation, objective provocation, and the personal traits of risk-affinity and low self-control/impulsivity each increase the probability of violence. However, they should not merely be regarded as additive factors increasing the likelihood of aggression, because they work together in bringing about violent behavior. Both risk-affinity and low self-control further increase the probability of violent behavior within the past 12 months when individuals feel easily provoked (subjective provocation). However, self-control seems to be somewhat more important as a coping resource with respect to subjective provocation. For individuals with the highest level of self-control, subjective provocation did not have an effect on violence. Also, the effect of low self-control seems to be mostly due to a greater probability of reacting with violence when feeling provoked; for individuals with minimal sensitivity to provocation, low self-control did not increase the probability of violence. The interaction effect between self-control and subjective provocation remained significant when controlling for that between risk-affinity and subjective provocation, supporting the argument that risk-aversion and self-control both function as coping resources, but for different reasons. Self-control should enable individuals to control their anger and reflect on the negative consequences of aggression. Risk-affinity should instead make violent reactions more likely, because risk-affine individuals would be less anxious about the negative consequences of violence (such as physical injury or the risk of sanctions) or might even enjoy the thrill.

The results of a conditioning effect of self-control on the link between objective provocation and projected violence in the applied vignette were less clear. First, without controlling for the conditioning effect of risk-affinity, only the interaction between selfcontrol and a moderate level of provocation was significant. The analysis did not reveal an interaction effect between high objective provocation and low self-control. The reason for this is unclear; the fact that the slight in this scenario condition is very strong might have contributed to this result, as in this case, acting aggressively might be morally justified (Sykes and Matza 1957) or even necessary for the individual in order to avoid future victimization (Anderson 2000), and might not mean that individuals are unable to control 
their aggressive impulses. However, the presentation of only three different experimentally varied degrees of objective provocation did not allow testing for such a ceiling effect. When simultaneously controlling for the conditioning effects of risk-affinity, those of selfcontrol were further attenuated and that between self-control and a moderate degree of objective provocation was no longer significant at conventional levels. Risk-affinity, however, increased the probability of projecting a violent reaction for both moderate and high levels of objective provocation, and the interaction effects remained stable and significant when controlling for those of self-control. While it was anticipated that conditioning effects are more difficult to reveal when applying an objective measure instead of a subjective measure of strain, differences between the conditioning factors in this matter were not expected and deserve closer scrutiny in future research. One possible explanation could be that the mechanism underlying self-control's functioning as a coping resource, namely inhibition of rash impulses, is more sensitive to the personal evaluation of the respective stressor (in the present case, whether the individual needs to control angry aggressive impulses or not), while the conditioning effect of fearlessness and risk-affinity, based on differences in general motivation to violent behavior, is less affected by the personal evaluation of a stressor. However overall, the results of this study convey that subjective measures of strain should more often be employed in research on GST, particularly when analyzing coping resources.

The present study also more generally underlines the importance of using adequate measures of all underlying processes in theory-guided research and, in the present context, of focusing on certain types of strain as well as certain types of delinquency when testing propositions of strain theory (Agnew 2013; Felson et al. 2012). Even if using composite measures of strain and delinquency in regression analyses might regularly reveal statistically significant average effects of strain on delinquency and support the general validity of GST, doing so hampers a deeper understanding of the underlying processes and conditioning factors (Felson et al. 2012). When studying violence, a conditioning process should be revealed more easily by studying a type of strain that is particularly conducive to violence, such as interpersonal provocation (Agnew 1990; Anderson and Bushman 2002; Tedeschi and Felson 1994). Self-control can be expected to condition this link, as it should enable individuals to control their anger and not turn their aggressive impulses into action (Denson et al. 2011b; DeWall et al. 2007). When studying income-generating crime, the effect of financial strain might be conditioned by self-control, because self-control might affect the likelihood of making use of the benefits promised by a chance to 'make some easy money' via illegitimate means. Individuals' routine activities (Cohen and Felson 1979) and the settings in which they find themselves, however, might be more proximate and stronger conditioning factors for the relationship between financial strain and crime. Equally important is the use of adequate measures for the conditioning factors under study: low self-control should make delinquent coping more likely because it concerns an individual's tendency to act on impulse and reflect on the long-term negative consequences of delinquent coping. Risk-affinity should instead make delinquent coping more likely because risk-affine individuals do not fear the negative consequences of crime or might even be attracted by its excitement and thrill. As long as measures of coping resources do not orient towards the mechanism underlying the coping process, it will remain difficult to reveal conditioning effects and to interpret them correctly if found.

Some limitations of this study should be kept in mind. First, although it is more likely that subjective provocation and low self-control affect the likelihood of acting violently than the other way around, the analyses of the prevalence of violence within the last 12 months did not reflect the correct temporal order of low self-control, subjective 
provocation, and violence. Therefore, the present cross-sectional study cannot rule out the possibility of reversed causality.

Second, it was not possible to directly compare the effects of objective provocation and subjective sensitivity to provocation as well as the effects of their respective conditioning factors, since objective provocation and subjective provocation were measured on different scales. It was plausible to assume a rank ordering between the different categories of objective provocation (and reflected in the increasing levels of projecting a violent response), such that our scenario version of a 'high' degree of provocation, in which the scenario character is pushed twice, is considered as more provoking than that of a 'moderate' provocation, in which the scenario protagonist is pushed and ignored by the other scenario character which, in turn, is considered as more severe than the situation in which the protagonist is told to turn down the music. Nevertheless, the ordered categories cannot be expected to lie at equal distances from each other on an underlying continuous latent scale of objective degree of provocation. Applying a measure of objective provocation on interval scale level would allow for directly comparing the effects of subjective provocation (and their conditioning factors) to those of objective provocation. Furthermore, it would allow testing for flooring or ceiling effects which could possibly play a role with regard to the conditioning effect of self-control.

Third, the present study did not disentangle the magnitude of subjective strain from the associated emotional response, but assessed subjective sensitivity to provocation through the amount of frustration and anger felt in different social encounters. As discussed, Agnew's (2001) introduction of a subjective component to the experience of strain makes separating subjective strain from the associated emotional 'response' problematic, because subjective evaluations of an entity and feelings tend to go hand in hand. Therefore, the causal ordering of the subjective evaluation of strain and emotions aroused is often unclear (Zajonc 1980; Schwarz and Clore 1988). The underlying assumption of the present measure of subjective provocation was that, if a respondent does not get angry across the different situational descriptions presented, he/she should not be sensitive to provocation either. However, the emotional reactions to such encounters may be more complex and the present study was not able to take this into account: individuals may feel provoked and get angry, but, at the same time, fear the provoking agent too much for a counterattack. Next to (rather) stable dispositions such as self-control or risk-affinity, situational emotions such as fear might also inhibit or amplify aggressive responses. Therefore, research should pay closer attention to the possibility that individuals may have different emotions at the same time and that such emotions might also moderate the reaction to (subjective or objective) strain.

The present study focused on a small subset of the universe of strains which might lead to delinquent behavior and of coping resources which could condition the link between strain and crime. However, in the end, this case study illustrates that focusing has its merits: it leads to a better understanding of why individuals cope with strain by engaging in (a certain type of) delinquency or remain resilient when experiencing strain. Agnew (2013, p. 653) instead advised survey researchers to investigate sets of characteristics "that together create a strong propensity for criminal coping." However, I think that this advice contradicts his strategy to match "particular strains and types of crime" (Agnew 2013, p. 656). Instead, certain types of strain should also be matched with "certain types of coping resources.' Even if, at times, the prediction of delinquent coping might be improved, one can ask what has really been learnt by finding that the "designation as a 'life-course-persistent' offender" (Agnew 2013, p. 656) increases the likelihood of delinquent coping with strain, or that 'crime-prone individuals' tend more towards 
delinquent coping. At the least, the present findings demonstrated that combining several conditioning factors into one scale, as suggested by Agnew (2013, p. 656), mirroring an individual's "overall standing on those conditioning variables said to increase criminal coping" (Agnew 2013, p. 656) may not always be most informative and, at times, may hide interesting results.

Acknowledgments This work uses data from the study "Friendship and Violence in Adolescence", funded by the German Research Foundation (DFG), Grant KR 4040/2. I would like to thank the members of the project team for the discussion of earlier versions of this manuscript. I am grateful to the anonymous reviewers for their valuable comments on an earlier draft of this paper.

Open Access This article is distributed under the terms of the Creative Commons Attribution 4.0 International License (http://creativecommons.org/licenses/by/4.0/), which permits unrestricted use, distribution, and reproduction in any medium, provided you give appropriate credit to the original author(s) and the source, provide a link to the Creative Commons license, and indicate if changes were made.

\section{Appendix}

See Tables 3 and 4.

Table 3 Subjective provocation: item wording

\begin{tabular}{|c|c|c|c|c|}
\hline $\begin{array}{l}\text { Now think about the following things } \\
\text { happening to you. How would you feel about } \\
\text { it? }\end{array}$ & $\begin{array}{l}1 \\
\text { 'That doesn't } \\
\text { bother me' }\end{array}$ & $\begin{array}{l}2 \\
\text { 'I am a little } \\
\text { annoyed by } \\
\text { this' }\end{array}$ & $\begin{array}{l}3 \\
\text { 'That really } \\
\text { enrages } \\
\text { me' }\end{array}$ & Total \\
\hline $\begin{array}{l}\text { Someone badmouths things that are important } \\
\text { to you, while you are present }\end{array}$ & $\begin{array}{l}324 \\
(12.6)\end{array}$ & $\begin{array}{l}1328 \\
(51.7)\end{array}$ & $\begin{array}{l}916 \\
(35.7)\end{array}$ & $\begin{array}{l}2568 \\
(100.0)\end{array}$ \\
\hline $\begin{array}{l}\text { Someone tells you to turn down your mp3 } \\
\text { player }\end{array}$ & $\begin{array}{l}1951 \\
(75.8)\end{array}$ & $\begin{array}{l}513 \\
(19.9)\end{array}$ & $\begin{array}{l}110 \\
(4.3)\end{array}$ & $\begin{array}{l}2574 \\
(100.0)\end{array}$ \\
\hline Someone makes jokes about your family & $\begin{array}{l}81 \\
(3.1)\end{array}$ & $\begin{array}{l}558 \\
(21.7)\end{array}$ & $\begin{array}{l}1938 \\
(75.2)\end{array}$ & $\begin{array}{l}2577 \\
(100.0)\end{array}$ \\
\hline $\begin{array}{l}\text { Someone asks you to take your shoes off the } \\
\text { seat on a train }\end{array}$ & $\begin{array}{l}1970 \\
(76.5)\end{array}$ & $\begin{array}{l}527 \\
(20.5)\end{array}$ & $\begin{array}{l}77 \\
(3.0)\end{array}$ & $\begin{array}{l}2574 \\
(100.0)\end{array}$ \\
\hline Someone stares at you or watches you & $\begin{array}{l}667 \\
(26.0)\end{array}$ & $\begin{array}{l}1363 \\
(53.1)\end{array}$ & $\begin{array}{l}538 \\
(21.0)\end{array}$ & $\begin{array}{l}2568 \\
(100.0)\end{array}$ \\
\hline Someone sits down too close next to you & $\begin{array}{l}1123 \\
(43.9)\end{array}$ & $\begin{array}{l}1181 \\
(46.1)\end{array}$ & $\begin{array}{l}257 \\
(10.0)\end{array}$ & $\begin{array}{l}2561 \\
(100.0)\end{array}$ \\
\hline $\begin{array}{l}\text { Someone barges in while you are having a } \\
\text { conversation with friends }\end{array}$ & $\begin{array}{l}446 \\
(17.4)\end{array}$ & $\begin{array}{l}1593 \\
(62.1)\end{array}$ & $\begin{array}{l}528 \\
(20.6)\end{array}$ & $\begin{array}{l}2567 \\
(100.0)\end{array}$ \\
\hline $\begin{array}{l}\text { Someone comes toward you on the sidewalk so } \\
\text { that you are forced to step aside }\end{array}$ & $\begin{array}{l}949 \\
(37.1)\end{array}$ & $\begin{array}{l}1153 \\
(45.0)\end{array}$ & $\begin{array}{l}458 \\
(17.9)\end{array}$ & $\begin{array}{l}2560 \\
(100.0)\end{array}$ \\
\hline Cronbach's alpha & & & & 0.69 \\
\hline
\end{tabular}

Absolute frequencies, percentages in brackets 
Table 4 Logistic regression of violence within the past 12 months on subjective provocation by levels of self-control, and including a product term between low self-control and subjective provocation

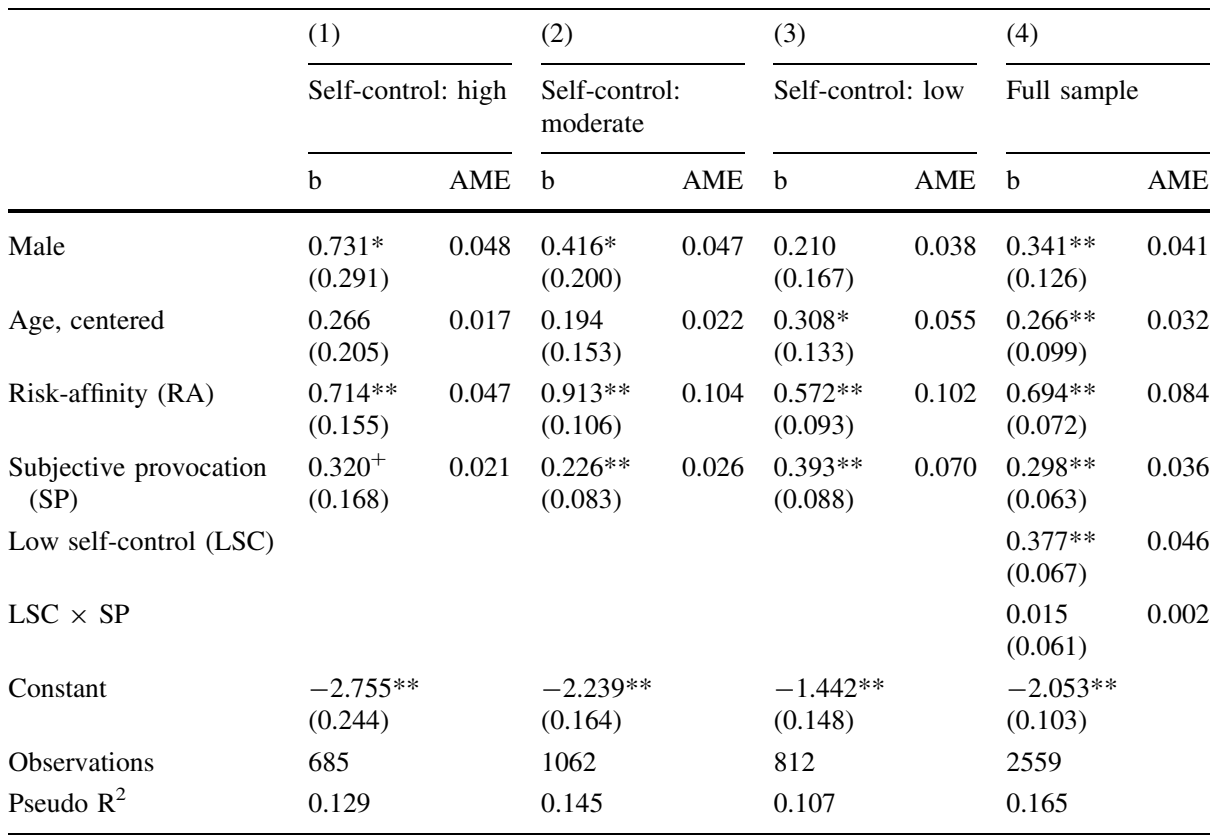

$\overline{+} p<0.10, * p<0.05, * * p<0.01$; cluster-robust standard errors in parentheses. AME average marginal effect, differences between AMEs of subjective provocation: $\chi^{2}(1)=0.11$ (high/moderate self-control); $\chi^{2}$ $(1)=6.28$ (moderate/low self-control); $\chi^{2}(1)=7.14$ (high/low self-control)

\section{References}

Agnew R (1985) A revised strain theory of delinquency. Soc Forces 64:151-167

Agnew R (1990) The origins of delinquent events: an examination of offender accounts. J Res Crime Delinq 27:267-294

Agnew R (1992) Foundation for a general strain theory of crime and delinquency. Criminology 30:47-87 Agnew R (2001) Building on the foundation of general strain theory: specifying the types of strain most likely to lead to crime and delinquency. J Res Crime Delinq 38:319-361

Agnew R (2006) Pressured into crime: an overview of strain theory. Roxbury, Los Angeles, CA

Agnew R (2013) When criminal coping is likely: an extension of general strain theory. Deviant Behav 34:653-670

Agnew R, Brezina T, Wright JP, Cullen FT (2002) Strain, personality traits and delinquency: extending general strain theory. Criminology 40:43-71

Ai C, Norton EC (2003) Interaction terms in logit and probit models. Econ Lett 80:123-129

Allison PD (1999) Comparing logit and probit coefficients across groups. Sociol Methods Res 28:186-208

Anderson E (2000) Code of the street: decency, violence, and the moral life of the inner city. Norton, London

Anderson CA, Bushman BJ (2002) Human aggression. Annu Rev Psychol 53:27-51

Arneklev BJ, Grasmick HG, Tittle CR, Bursik RJ (1993) Low self-control and imprudent behavior. J Quant Criminol 9:225-247

Auspurg K, Hinz T (2011) Group comparisons for regression models with binary dependent variablesproblems and pitfalls illustrated by differences in educational opportunities between cohorts. Z Soziol 40:62-73 
Baron SW (2009) Street youths' violent responses to violent personal, vicarious, and anticipated strain. J Crim Justice 37:442-451

Bornewasser M, Eifler S, Reichel K (2007) Wie allgemein ist die „General Theory of Crime“? Monatsschrift für Kriminologie und Strafrechtsreform 90:443-465

Botchkovar EV, Tittle CR, Antonaccio O (2009) General strain theory: additional evidence using crosscultural data. Criminology 47:131-176

Broidy LM (2001) A test of general strain theory. Criminology 39:9-36

Burt CH, Simons RL (2013) Self-control, thrill seeking, and crime. Motivation matters. Crim Justice Behav 40:1326-1348

Burt CH, Sweeten G, Simons RL (2014) Self-control through emerging adulthood: instability, multidimensionality, and criminological significance. Criminology 52:450-487

Buss AH (2012) Pathways to individuality. Evolution and development of personality traits. American Psychological Association, Washington, D.C.

Capowich GE, Mazerolle P, Piquero A (2001) General strain theory, situational anger, and social networks: an assessment of conditioning influences. J Crim Justice 29:445-461

Cheung NWT, Cheung YW (2010) Strain, self-control, and gender differences in delinquency among chinese adolescents: extending general strain theory. Sociol Perspect 53:321-345

Cohen L, Felson M (1979) Social change and crime rate trends: a routine activity approach. Am Sociol Rev 44:588-605

Conner B, Stein J, Longshore D (2009) Examining self-control as a multidimensional predictor of crime and drug use in adolescents with criminal histories. J Behav Health Serv Res 36:137-149

De Coster S, Kort-Butler L (2006) How general is general strain theory? Assessing determinacy and indeterminacy across life domains. J Res Crime Delinq 43:297-325

Delisi M, Hochstetler A, Murphy D (2003) Self-control behind bars: a validation study of the Grasmick et al. scale. Justice Q 20:241-263

Denson TF, Capper MM, Oaten M, Friese M, Schofield TP (2011a) Self-control training decreases aggression in response to provocation in aggressive individuals. J Res Personal 45:252-256

Denson TF, Pedersen WC, Friese M, Hahm A, Roberts L (2011b) Understanding impulsive aggression: angry rumination and reduced self-control capacity are mechanisms underlying the provocation-aggression relationship. Personal Soc Psychol Bull 37:850-862

DeWall CN, Baumeister RF, Stillman TF, Gailliot MT (2007) Violence restrained: effects of self-regulation and its depletion on aggression. J Exp Soc Psychol 43:62-76

Diekmann A (2010) Empirische Sozialforschung. Rowohlt-Taschenbuch-Verlag, Reinbek bei Hamburg

Digman JM (1990) Personality structure: emergence of the five-factor model. Annu Rev Psychol 41:417-440

Ellwanger SJ, Pratt TC (2014) Self-control, negative affect, and young driver aggression: an assessment of competing theoretical claims. Int J Offender Ther Comp Criminol 58:85-106

Felson RB, Osgood DW (2008) Violent crime. In: Goode E (ed) Out of control: assessing the general theory of crime. Stanford University Press, Stanford, pp 160-172

Felson RB, Osgood DW, Horney J, Wiernik C (2012) Having a bad month: general versus specific effects of stress on crime. J Quant Criminol 28:347-363

Froggio G, Agnew R (2007) The relationship between crime and “objective" versus "subjective" strains. J Crim Justice 35:81-87

Gottfredson MR (2011) Sanctions, situations, and agency in control theories of crime. Eur J Criminol $8: 128-143$

Gottfredson MR, Hirschi T (1990) A general theory of crime. Stanford University Press, Stanford

Grasmick HG, Tittle CR, Bursik JR, Arneklev B (1993) Testing the core empirical implications of Gottfredson and Hirschi's general theory of crime. J Res Crime Delinq 30:5-29

Hay C (2003) Family strain, gender, and delinquency. Sociol Perspect 46:107-135

Hay C, Evans MM (2006) Violent victimization and involvement in delinquency: examining predictions from general strain theory. J Crim Justice 34:261-274

Hay C, Meldrum R (2010) Bullying victimization and adolescent self-harm: testing hypotheses from general strain theory. J Youth Adolesc 39:446-459

Hellevik O (2009) Linear versus logistic regression when the dependent variable is a dichotomy. Qual Quant 43:59-74

Hirschi T (2008) Comment: self-control in the lab. In: Horne C, Lovaglia MJ (eds) Experiments in criminology and law: a research revolution. Rowman \& Littlefield Publishers, Lanham, pp 63-71

Hirschi T (1995) The family. In: Wilson JQ, Petersilia J (eds) Crime. ICS Press, San Francisco, pp 121-140

Hirschi T (2004) Self-control and crime. In: Baumeister RF, Vohs KD (eds) Handbook of self-regulation: research, theory, and applications. The Guilford Press, New York, pp 537-552 
Hirschi T, Gottfredson MR (1993) Commentary: testing the general theory of crime. J Res Crime Delinq $30: 47-54$

Jang SJ, Johnson B (2003) Strain, negative emotions, and deviant coping among african americans: a test of general strain theory. J Quant Criminol 19:79-105

Jang SJ, Rhodes JR (2012) General strain and non-strain theories: a study of crime in emerging adulthood. J Crim Justice 40:176-186

Ksinan A, Vazsonyi A, Jiskrova G (2014) A test of the dual system model of adolescent risk-taking. Paper presented at the 14th annual conference of the European Society of Criminology, Prague, Czech Republic, 10-13 September 2014

Lin W-H, Mieczkowski T (2011) Subjective strains, conditioning factors, and juvenile delinquency: general strain theory in Taiwan. Asian J Criminol 6:69-87

Longshore D, Turner Rand S, Stein JA (1996) Self-control in a criminal sample: an examination of construct validity. Criminology 34:209

Marcus B (2003) An empirical examination of the construct validity of two alternative self-control measures. Educ Psychol Meas 63:674-706

Marcus B (2004) Self-control in the general theory of crime. Theory Criminol 8:33-55

Mazerolle P, Maahs J (2000) General strain and delinquency: an alternative examination of conditioning influences. Justice Q 17:753-778

Mazerolle P, Piquero A (1997) Violent responses to strain: an examination of conditioning influences. Violence Vict 12:323-343

Mazerolle P, Burton VS Jr, Cullen FT, Evans TD, Payne GL (2000) Strain, anger, and delinquent adaptations: specifying general strain theory. J Crim Justice 28:89-101

Mood C (2010) Logistic regression: why we cannot do what we think we can do, and what we can do about it. Eur Sociol Rev 26:67-82

Moon B, Morash M, McCluskey CP, Hwang H-W (2009) A comprehensive test of general strain theory: key strains, situational- and trait-based negative emotions, conditioning factors, and delinquency. J Res Crime Delinq 46:182-212

Moon B, Morash M, McCluskey JD (2012) General strain theory and school bullying: an empirical test in South Korea. Crime Delinq 58:827-855

Nagler J (1994) Scobit: an alternative estimator to logit and probit. Am J Polit Sci 38:230-255

Nisbett RE, Cohen D (1996) Culture of honor: the psychology of violence in the south. Westview Press, Boulder

Patton JH, Stanford MS, Barratt ES (1995) Factor structure of the Barratt Impulsiveness Scale. J Clin Psychol 51:768-774

Peter T, LaGrange T, Silverman R (2003) Investigating the interdependence of strain and self-control. Can J Criminol Crim Justice 45:431-464

Piquero AR (2008) Measuring self-control. In: Goode E (ed) Out of control. Stanford University Press, Stanford, pp 26-37

Piquero AR, Rosay AB (1998) The reliability and validity of Grasmick et al.'s self-control scale: a comment on Longshore et al. Criminology 36:157-174

Piquero NL, Sealock MD (2000) Generalizing general strain theory: an examination of an offending population. Justice Q 17:449-484

Pogarsky G (2007) Deterrence and individual differences among convicted offenders. J Quant Criminol 23:59-74

Romero E, Gomez-Fraguela JA, Luengo MA, Sobral J (2003) The self-control construct in the general theory of crime: an investigation in terms of personality psychology. Psychol Crime Law 9:61-86

Schulz S (2014) Individual differences in the deterrence process: Which individuals learn (most) from their offending experiences? J Quant Criminol 30:215-236

Schwarz N, Clore GL (1988) How do I feel about it? The informative function of mood. In: Fiedler K, Forgas JP (eds) Affect cognition and social behavior: new evidence and integrative attempts. Hogrefe, Toronto, pp 44-62

Spielberger CD, Jacobs G, Russel S, Crane RS (1983) Assessment of anger: the state-trait anger scale. In: Butcher JN, Spielberger CD (eds) Advances in personality assessment, vol 2. Lawrence Erlbaum Associates, Hillsdale, NJ, pp 161-190

Spielberger CD, Reheiser EC, Sydeman SJ (1995) Measuring the experience, expression, and control of anger. Issues Compr Pediatr Nurs 18:207-232

Steinberg L, Albert D, Cauffman E, Banich M, Graham S, Woolard J (2008) Age differences in sensation seeking and impulsivity as indexed by behavior and self-report: evidence for a dual systems model. Dev Psychol 44:1764-1778 
Stogner J, Gibson CL (2010) Healthy, wealthy, and wise: Incorporating health issues as a source of strain in Agnew's general strain theory. J Crim Justice 38:1150-1159

Stryker S, Burke PJ (2000) The past, present, and future of an identity theory. Soc Psychol Q 63:284-297

Sykes GM, Matza D (1957) Techniques of neutralization: a theory of delinquency. Am Sociol Rev 22:664-670

Tangney JP, Baumeister RF, Boone AL (2004) High self-control predicts good adjustment, less pathology, better grades, and interpersonal success. J Personal 72:271-324

Tedeschi JT, Felson RB (1994) Violence, aggression, and coercive actions. American Psychological Association, Washington, DC

Tertilt H (1996) Turkish power boys: Ethnographie einer Jugendbande. Suhrkamp, Frankfurt am Main

Turanovic JJ, Pratt TC (2013) The consequences of maladaptive coping: integrating general strain and selfcontrol theories to specify a causal pathway between victimization and offending. J Quant Criminol 29:321-345

Ward J, Nobles M, Fox K (2014) Disentangling self-control from its elements: a bifactor analysis. J Quant Criminol. doi:10.1007/s10940-014-9241-6

Wikström P-OH, Oberwittler D, Treiber K, Hardie B (2012) Breaking rules: the social and situational dynamics of young people's urban crime. Oxford University Press, Oxford

Wilkinson DL (2002) Decision making in violent events among adolescent males: an examination of sparks and other motivational factors. In: Piquero AR, Tibbetts SG (eds) Rational choice and criminal behavior: recent research and future challenges. Routledge, New York, pp 163-196

Wood PB, Pfefferbaum B, Arneklev BJ (1993) Risk-taking and self-control: social psychological correlates of delinquency. J Crime Justice 16:111-130

Wooldridge JM (2013) Introductory econometrics: a modern approach. South-Western Cengage Learning, Mason

Zajonc RB (1980) Feeling and thinking: preferences need no inferences. Am Psychol 35:151-175

Zuckerman M (2009) Sensation seeking. In: Leary MR, Hoyle RH (eds) Handbook of individual differences in social behavior. The Guildford Press, New York/London, pp 455-465 